\title{
Pre-clinical outcome of Alexidine-treated intravenous catheter for antimicrobial and antithrombogenic effectiveness
}

Nisha Gupta, MS, PhD and Hilary Weber, BS

Teleflex, Inc., 2400 Bernville Road, Reading, PA 19605, USA

\section{Introduction:}

Intravenous catheters (IVCs) have advanced in recent years by incorporating chlorhexidine, silver, other anitimicrobials, heparin etc. for minimizing catheter-related complications such as infection, occlusion and thrombosis. Alexidine is a cationic bisbiguanide antimicrobial agent, well recognized for its antibacterial and antifungal characteristics. ${ }^{1}$ As such, it is closely related to chlorhexidine in its molecular structure with the exception that it consists of terminal 2-ethylhexyl groups whereas chlorhexidine includes chlorophenyl end groups. ${ }^{2}$ This difference in molecular structure has been attributed to faster microbicidal effect ${ }^{3}$ and extremely low potential for causing hypersensitivity in humans from Alexidine when compared to chlorhexidine. ${ }^{4}$ Microbes with demonstrated resistance towards other antimicrobial agents have shown no such resistance towards alexidine. ${ }^{3}$ Alexidine is also shown to suppress inflammatory responses in presence of infection by neutralizing bacterial membrane components which serve as stimulators of Toll-like receptors on macrophages leading to their activation.

\section{Purpose:}

The purpose of this investigation was to assess antimicrobial and antithrombogenic effectiveness of a new IVC treated with Alexidine, an antimicrobial agent, in a sheep model with Staphylococcus aureus (SA) infection

\section{Method:}

Untreated (Control) and Alexidine-treated (ALX) IVCs were placed into 12 sheep for either 7- or 30days ( $n=3$ per group per timepoint) through left jugular vein in to SVC under ultrasound guidance. Prior to placement, insertion sites were prepped with $70 \%$ IPA, dried and then inoculated with SA at $10^{\wedge} 6$ CFUs. At the end of in-animal phase, explanted catheter, fibrin sheath and vein tissue were analyzed for microbial presence (via viable cell counts), fibrin sheath accumulation (via weight and length measurements) and venous thrombosis. Additionally, pre-implant/pre-explant blood chemistry, blood culture, and clinical observations (body temperature, weight, appetite, general behavior) were recorded through-out the study period.

\section{Key Results:}

- Viable cell counts from the explanted catheters, sheath and surrounding tissues ranged between $10^{\wedge} 5-10^{\wedge} 8 \mathrm{CFU}$ from the 6 Control animals and 0 CFU from the 6 ALX animals in both time cohorts.

- In the 30-day cohort, 2/3 Control animals developed fever accompanied with positive SA cultures from blood samples drawn from peripheral vein indicating CRBSI, while the 3 ALX animals remained healthy through the study duration.

- In both time cohorts, all Control animals exhibited presence of extended fibrin sheath, phlebitis, thickened vein wall, and complete vein occlusion in 2/3 animals in the 30-day cohort.

- In both time cohorts, all ALX animals showed normal vein wall, fibrin sheath presence limited to only at the insertion site and patent vessel.

- As compared to Control group, reduction in fibrin sheath weight for the ALX group was $95 \%$ at 7 -day and $99 \%$ at 30-day timepoints, while reduction in fibrin sheath length was $82 \%$ at 7 -day and $92 \%$ at 30-day timepoints.

\section{TABLE 1:}

VIABLE CELL COUNTS FROM EXPLANTED CATHETERS AND FIBRIN SHEATH AND CALCULATED LOG REDUCTION AS COMPARED TO CONTROL CATHETER

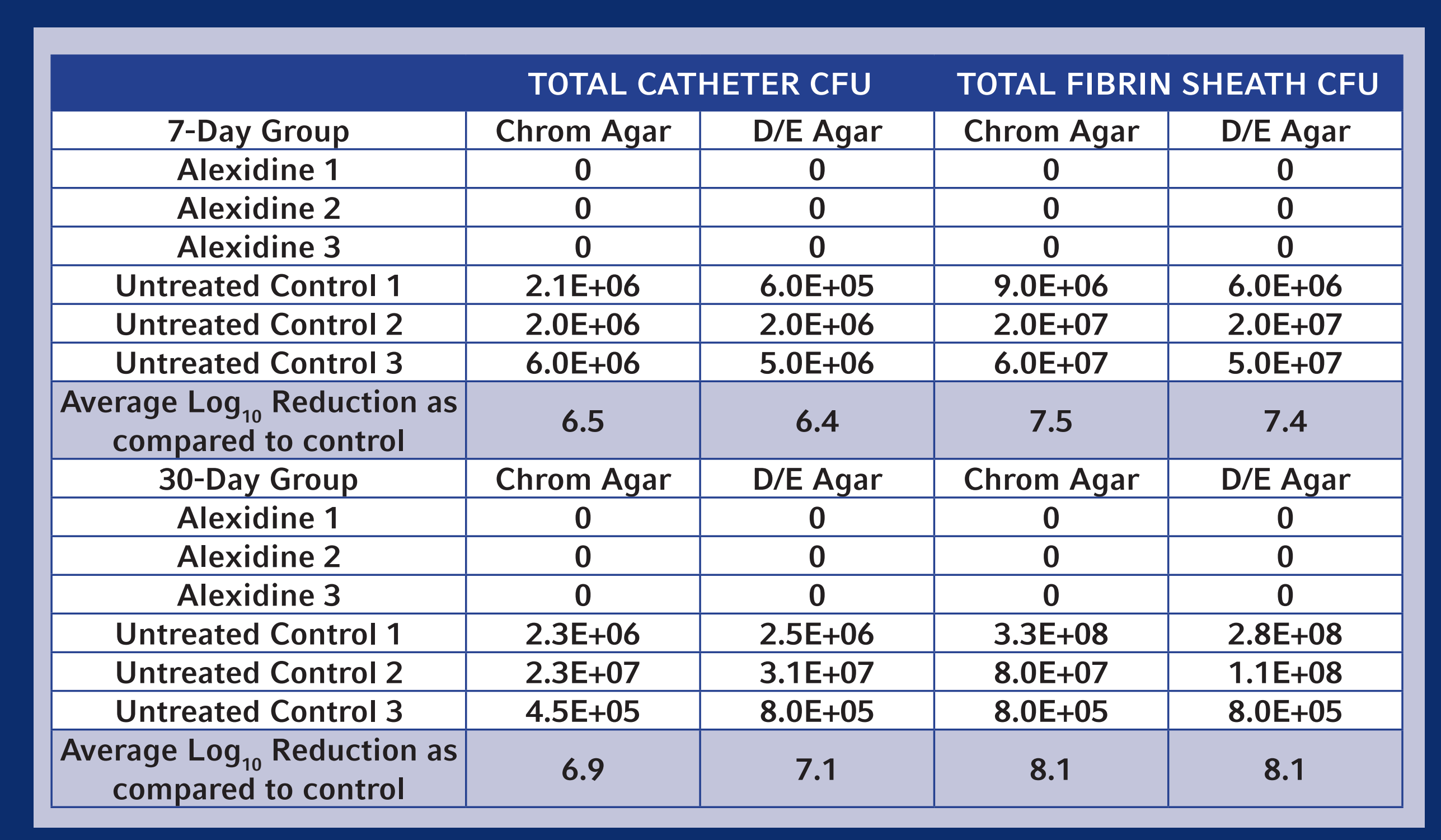

TABLE 2:

FIBRIN SHEATH/THROMBUS ACCUMULATION ON EXPLANTED CATHETERS

\begin{tabular}{|c|c|c|c|c|}
\hline $\begin{array}{c}\text { TIME } \\
\text { COHORT }\end{array}$ & CATHETER GROUP & $\begin{array}{l}\text { \# OF } \\
\text { SHEEP }\end{array}$ & $\begin{array}{l}\text { AVERAGE } \\
\text { THROMBUS } \\
\text { WEIGHT (G) }\end{array}$ & $\begin{array}{c}\text { AVERAGE } \\
\text { THROMBUS } \\
\text { LENGTH (CM) }\end{array}$ \\
\hline \multirow{3}{*}{$\begin{array}{l}7+-2 \\
\text { days }\end{array}$} & Alexidine-treated & 3 & 0.04 & 1.33 \\
\hline & Untreated Control & 3 & 0.81 & 7.33 \\
\hline & \multicolumn{2}{|c|}{$\begin{array}{l}\text { \% Thrombus reduction } \\
\text { as compared to Control }\end{array}$} & $95 \%$ & $82 \%$ \\
\hline \multirow{3}{*}{ 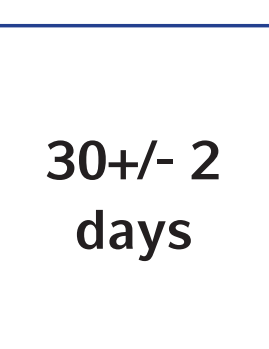 } & Alexidine-treated & 3 & 0.15 & 1.7 \\
\hline & Untreated Control & 3 & 22.6 & 21.8 \\
\hline & \multicolumn{2}{|c|}{ \% Thrombus reduction } & $99 \%$ & $92 \%$ \\
\hline
\end{tabular}

FIGURE 2:

POST-OPERATIVE DAILY BODY TEMPERATURE OVER 30 DAYS

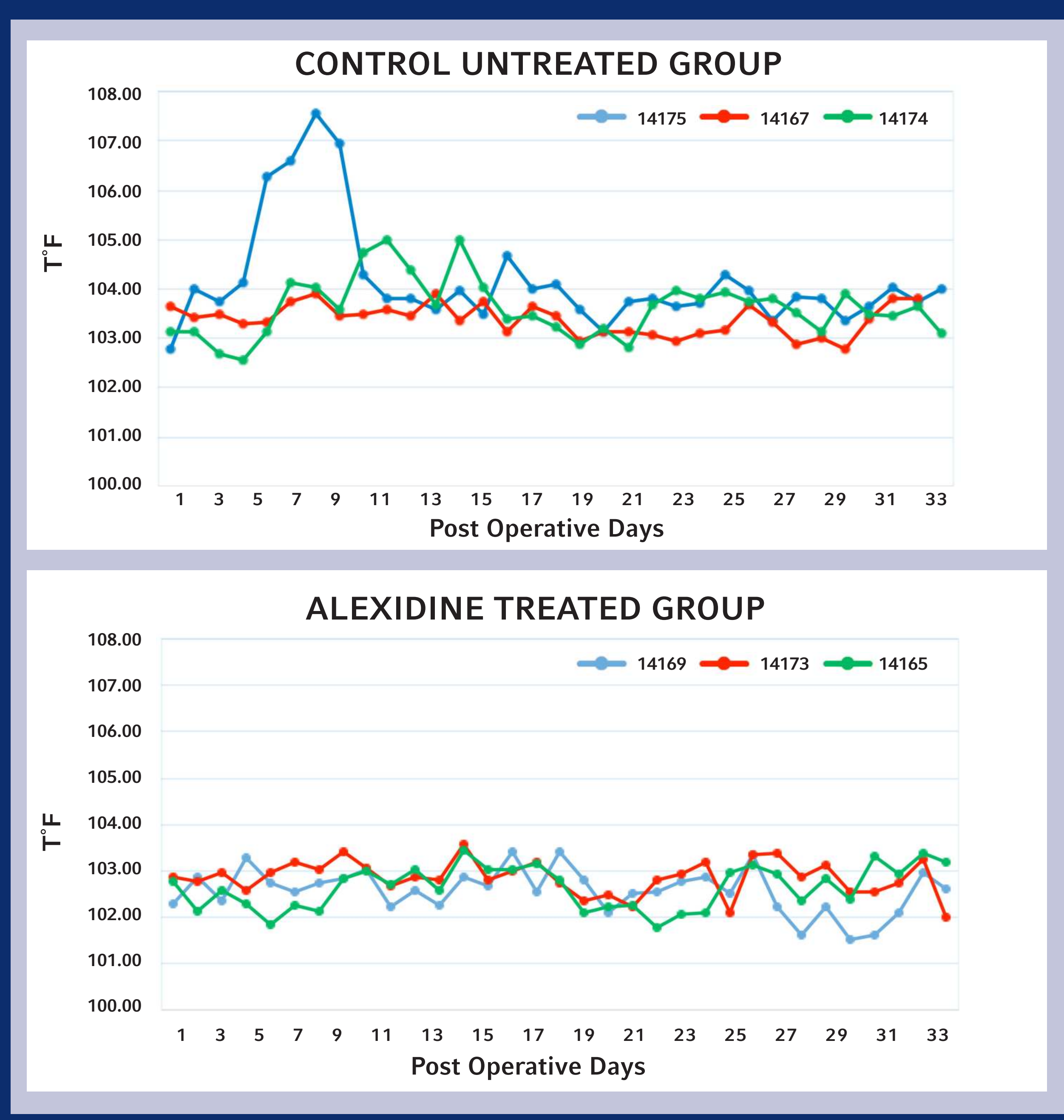

\section{Disclosure Statement:}

Authors are employees of Teleflex, Inc.

\section{References:}

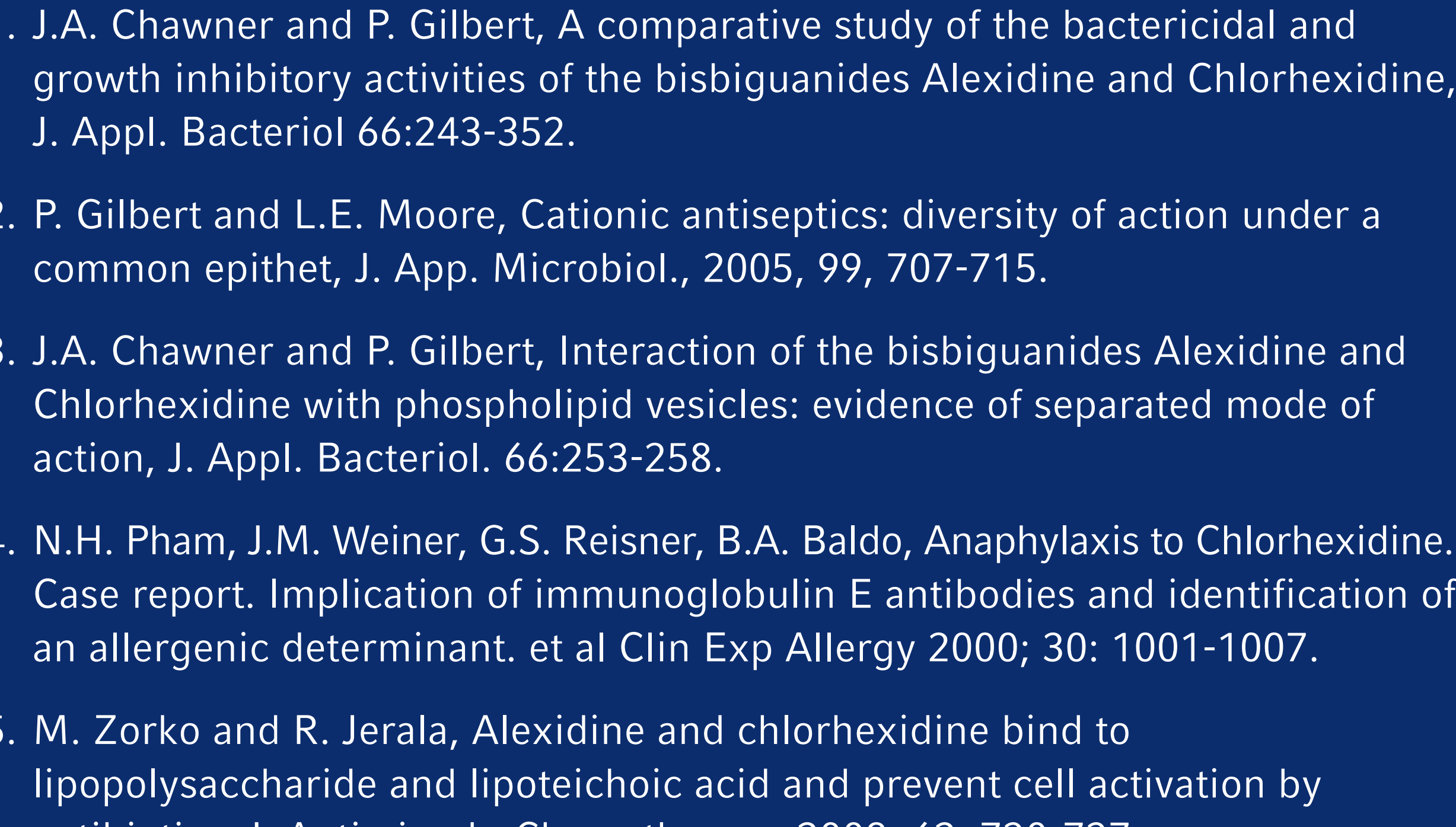

\section{Conclusions:}

Alexidine-treated IVC was highly efficacious in reducing microbial colonization, fibrin sheath formation, CRBSI and venous thrombosis over a period of 30 days in the sheep model with Staphylococcus aureus infection.

FIGURE 1: VISUAL 30-DAY EXPLANT DATA UNTREATED CONTROL

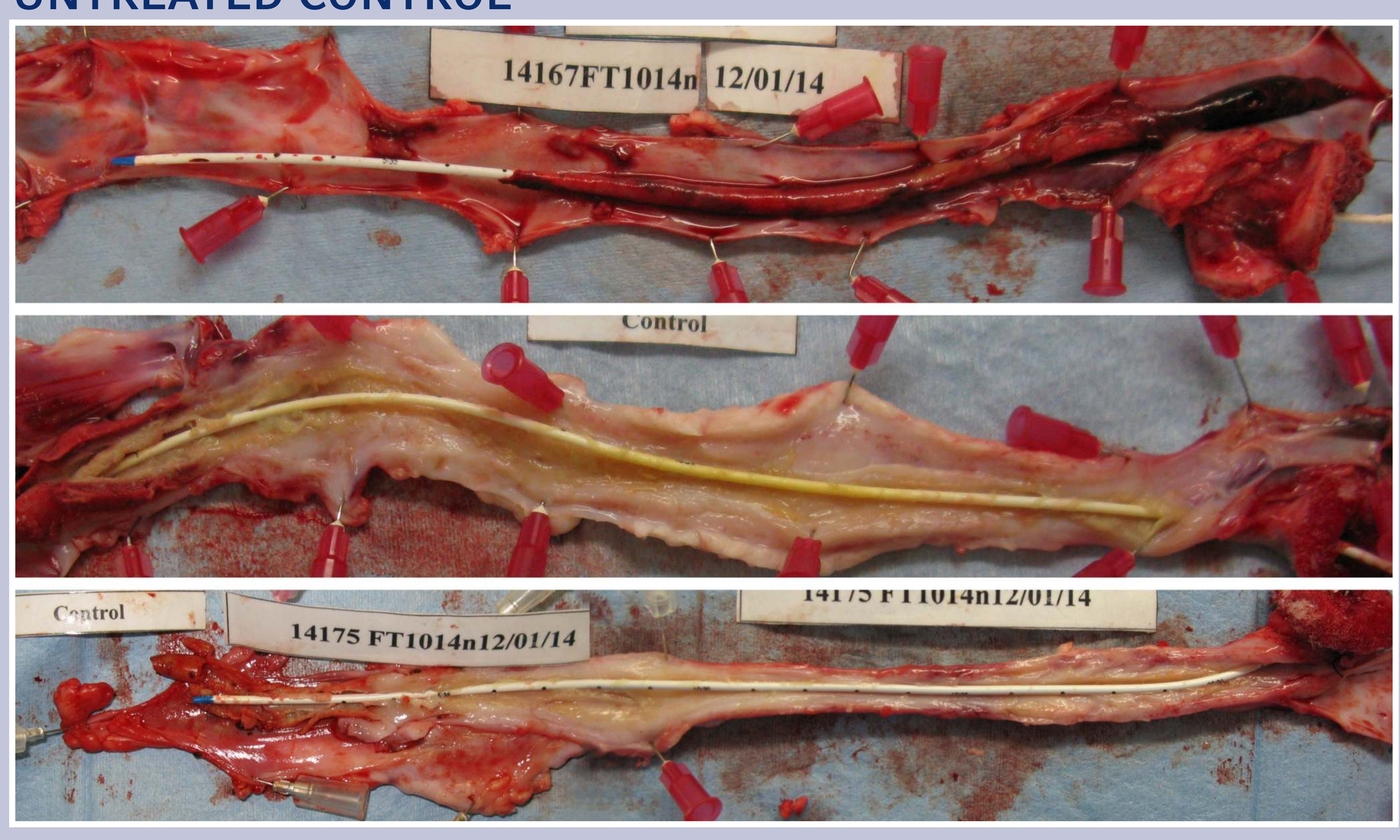

ALEXIDINE

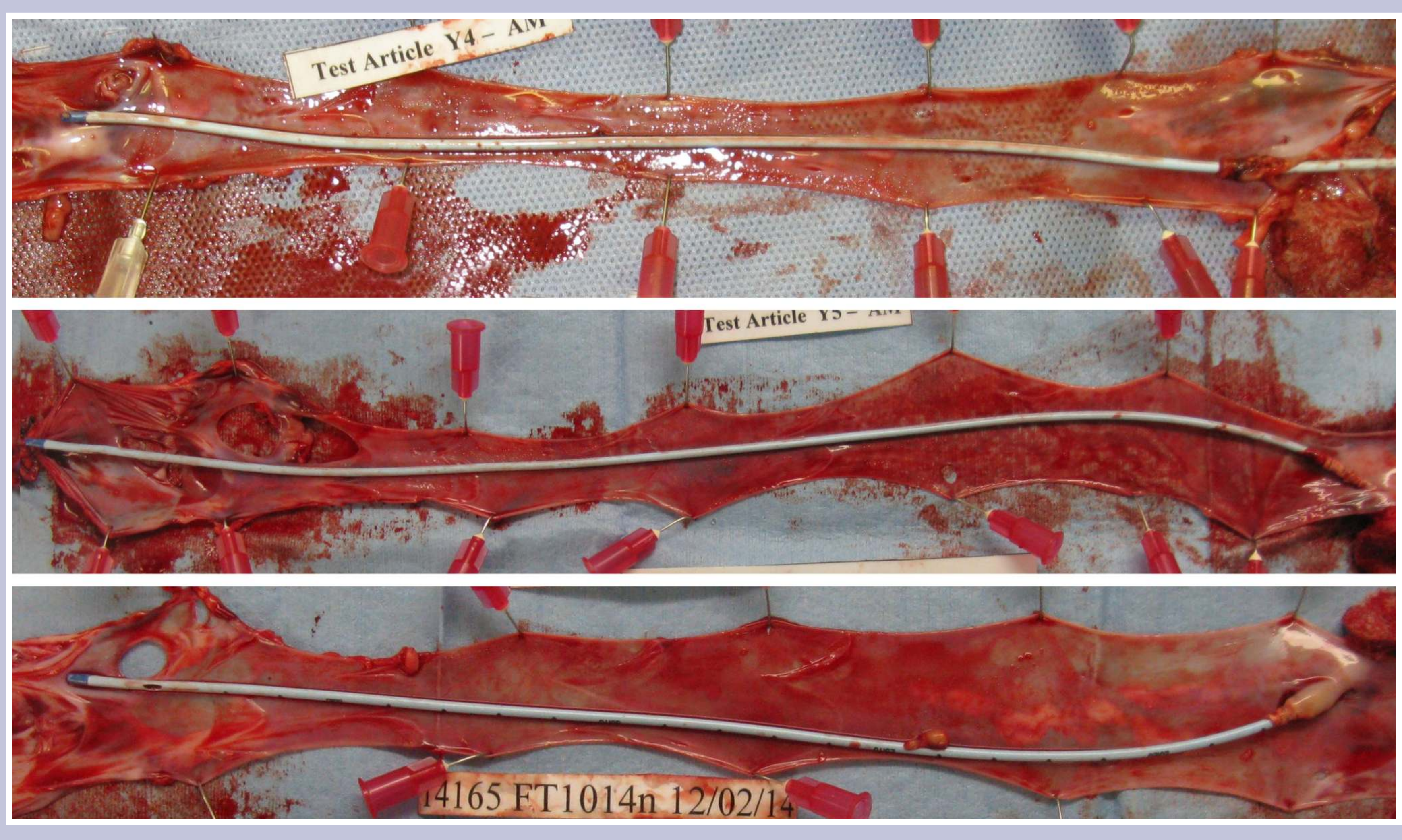

